\title{
Qualitative Development of Students' Digital Skills by Integrating a Spreadsheet Software in First Year Introduction to Engineering and Seminar Course
}

\author{
https://doi.org/10.3991/ijet.v16i18.24325 \\ Aziatul Niza Sadikin, Azizul Azri Mustaffa $\left.{ }^{\bowtie}\right)$, Hasrinah Hasbullah, \\ Zaki Yamani Zakaria, Mohd Kamaruddin Abd Hamid, Siti Hajjar Che Man, \\ Mimi Haryani Hassim, Muhammad Arif Ab Aziz, Khairiyah Mohd.Yusof \\ Universiti Teknologi Malaysia, Johor, Malaysia \\ azizulazri@utm.my
}

\begin{abstract}
The Introduction to Engineering (ITE) and Industrial Seminar and Profession (ISP) courses conducted at School of Chemical and Energy Engineering, Universiti Teknologi Malaysia, are integrated courses which implement the Cooperative Problem-based Learning (CPBL) methods in the same semester. Based on these integrated courses, the main aim of this paper is to investigate the qualitative impact of spreadsheet hands-on seminar on the first year students' digital skill. At the beginning of the semester, students are given sustainability-based project to work on, which requires them to collect and to report the data in a series of presentations and written reports. In order to present those data, they need to use analysis tools such as a spreadsheet software. The students are introduced with some in-depth applications of the Microsoft Excel software through the seminar sessions in the ISP course. With the knowledge that the students gain, they are expected to implement it in the CPBL project. A qualitative approach has been adopted to implement the study. Student's reflections were used as the data source to identify common attributes that they have managed to gain from seminar sessions. This study has found that all students had primarily learned about digital skills. They perceived hand-on activity during the seminar as a good platform to acquire knowledge on basic calculation and developed learning skill on Excel. Moreover, students recognized the skills they are learning will be useful in other courses and future careers.
\end{abstract}

Keywords-digital skills, Microsoft Excel, problem-based learning

\section{Introduction}

Digital skills are one of the main driving force of the 4 th industrial revolution. According to the National Policy on Industry 4.0 [1], Malaysia will be focusing on the transformation of the manufacturing sector through Industry 4.0. There are several identified enabling technologies, which include artificial intelligence, big data analytics, augmented reality, cybersecurity, additive manufacturing, system integration, sim- 
ulation, internet of things, advanced materials, autonomous robots and cloud computing. One of the focused areas is the chemical industries, including pharmaceuticals, food processing, etc. Besides technologies, other enablers include the skills and talents of the workers, which will be mainly recruited among the graduates in the STEM (science, technology, engineering and mathematics) programmes.

In line with the revised guideline by the Malaysian Qualification Agency (MQA) on the Malaysian Qualification Framework (MQF) 2.0 [2], one of the main changes is the addition of digital skills under the functional work skills cluster as one of the programme learning outcomes. Other skills specified under the same cluster is practical, interpersonal, communication, numeracy and leadership skills. In the MQF 2.0, digital skills are described as the capability of the students to employ digital technologies and tools to assist their studies, which include storing data and information, processing it and presenting it to others, which can be part of a problem-solving exercise.

From an international perspective, from 2011 to 2013, the Confederation of British Industries (CBI) found out that between 3 to $6 \%$ of employers (average 470 per year of respondents) were dissatisfied with the graduates' IT application skills that include word processing, spreadsheets, file management and use of internet search engines [3, 4, and 5]. According to the study done by Fletcher et al. [6] at the University of Strathclyde on the perception of their chemical engineering students and alumni, they found out that the acquisition of the technical skills is more than what is expected by the employers, which is excellent. However, according to both the students and alumni the attainment of the generic skills was lacking and not explicitly highlighted in the curriculum. According to Geoff Maitland, IChemE President (2014-2015) in the institution's blog [7], computer skills are one of the main skills in chemical engineering that chemical engineers should be good at. This is also supported by the study conducted by Dewi et al. [8] for generation $\mathrm{Z}$ chemistry students. Chemistry, just like engineering, requires computer tools to simplify the learning of complex theories and concept. Same goes for physics as presented by Drigas and Kontopoulou [9] in their study where they use information and communication technologies (ICT) to enhance the understanding of the physics concepts through simulation, virtual reality and video games techniques.

Laar et al. [10] in a study on 907 professionals, including designers, engineers and project managers that were involved in creative industries, found that even during creative work processes, the need of digital skills is common in the work routine. The top four skills where digital skills are highly utilised are on information management, communication expressiveness, information evaluation and problem solving. The same applications came up on the top five plus use in Collaboration when $\mathrm{Xu}$ et al. [11] did their study on 962 college students. Based on this, spreadsheet programs like Microsoft Excel seems to fit well to cater for these skills. Thus, it showed the necessity for the students to acquire the spreadsheet knowledge and skill as an indispensable tool in this digital age.

Dos Santos et al. [12], stated that chemical engineering students should be equipped with programming skills, causing them to embed an elective programming course for final year students at University of Sao Paulo. Ricardez-Sandoval et al. [13], which highlight the use of MATLAB programming tools designed to enhance problem solving skills among first year chemical engineering. However, students favour using Excel 
compared to other programming softwares as they are more familiar with it, which is good enough as a starting point. In fact, there are also many Excel-based approaches in teaching programming skills to the students to solve various problems [14, 15, 16 and 17]. A chemical engineer having both good technical and programming skills can develop new tools for chemical processes and product design. A good knowledge on using the Excel spreadsheet can be a doorway to further enhance advanced digital tools and skills. In fact, if one managed to master fully the application of Excel, many tasks can be completed and problems can be solved quickly and easily.

Uddin et al. [18] discussed that the user-friendly Excel also is capable in producing complex figures like Lissajous figures and a damped harmonic oscillator that are taught in Physics class. They discovered that using such simulation to explain the theory, had enhanced students' understanding. Hence, having proper spreadsheet skills will be able to enhance one's data presentation and reports in ensuring a more effective understanding of the target audience.

Although, Microsoft Excel is a commonly used tool in daily life nowadays, it is often utilised with minimal training and programming experience. As a result, the user may not realize its full potential and will not use the various powerful functions in Excel, or will struggle to learn on their own from scratch. A good spreadsheet design will minimize or perhaps eliminate these errors [19]. Lipton et al. [20] did a study on business school students by implementing a peer tutoring basic Excel knowledge to students with minimum skills and knowledge which struggles to perform even a simple task. Learning Excel is similar to learning a language. Therefore, students can benefit from the personal tutoring sessions conducted [20].

Frownfelter-Lorhke [19] reported the incremental approach of three Excel assignments from exposure to basics of good design to ultimately more complex assignments. This to ensure the students gain the full experience of the spreadsheet starting with being familiar and unafraid to face the software. Similar approach was employed during Excel seminar for ISP course. Some of Frownfelter-Lorhke's ex-student feedbacks seconded that the use of Excel daily in a workplace is unavoidable and having such training had been very helpful [19]. According to Formby et al. [21], Excel is an important tool whereby the skills of using it need to be mastered by college graduates as several reports showed advanced analytical skills using Excel results in increasing the job marketability. Feedback from the students clearly mentioned that incorporating Excel skill in their course will be extremely helpful in preparing them for their internship and fulltime employment in the future [21]. Therefore, it is important to introduce first year chemical engineering students to the skills of using Excel which will be a stepping stone to introduce students to more advanced programming tools or digital tools in general which in the end will prepare the graduates to face the job market that will revolve around Industry 4.0. Hence, main aim of this paper is to investigate the qualitative impact of spreadsheet hands-on seminar on the first year students' digital skill. This study was conducted based on students' perceptions only. 


\section{Course Design}

The Introduction to Engineering (ITE) and Industrial Seminar and Profession (ISP) are two compulsory courses for first year chemical engineering students at the School of Chemical and Energy Engineering, Universiti Teknologi Malaysia. ITE is a 3-credit course and ISP is 1-credit course. These courses are integrated and conducted using Cooperative Problem-based Learning (CPBL) method [22]. The integration of the courses is detailed in Table 1. These two courses are offered simultaneously and introduced the students to the engineering fields and highlight the skills that they need to acquire until the end of their studies, to be competitive in the job market.

In the ITE course (3 credits), students are given sustainability-based project [23, 24] to work on, which require them to collect and report those data in a series of presentations and written reports. In order to present those data, they need to use analysis tools such as a spreadsheet software. Besides that, Excel skills are essential part of digitals skills that the students need to acquire at the end of their studies and to be used in other courses in the chemical engineering curriculum. The ISP course ( 1 credit) focuses on engaging students with professional stakeholders who will share necessary knowledge and skills to help the students with their environmental sustainability-based problem. This weekly session will also train them with essential soft skills that are useful for their studies and essential upon their graduation later. Among the skills developed are effective presentation using PowerPoint, public speaking, problem solving, information searching using search engine and also knowledge about professional engineer, sustainable development, code of ethics, etc.

Normally there are between four to six sections or classes with two instructors in each section to facilitate the courses and each instructor is provided a lecturer guide containing details of the activities in both courses which have been designed before the semester starts. The activities are designed in detail according to the CPBL framework.

Every week, the activities in the ISP course will complement the activities in the ITE class. In a 14-week semester, the common plan for the ISP class in week 5, there will be a hands-on workshop on basic engineering calculations using Excel conducted by the instructors. In this workshop, the students are taught in-depth applications of the software tools which include pointers, formula and function, cell referencing, charts and graphs, curve fitting and finding roots using the goal seek function. Even though many students take the session for granted due to the fact they thought that they knew everything already, it seems that there are still many new skills that they have learnt, for example the usage of the cell referencing method etc. After the workshop, they will be given assignments which account for $30 \%$ of the total marks for the ISP class. With the knowledge that the students gain, they can implement it in the CPBL project, monitored through the ITE class. A detailed mapping of the activities between the two courses is provided in Table 1 and those related to the usage of the Excel software tools are bolded.

On the third week of the semester, there will be a workshop on reflection journal. The aims of this workshop are to introduce students what being reflective means and to some ways of reflecting by using reflective models. Gibbs' reflective cycle will be introduced to aid student's reflective process. Furthermore, the workshop is intended 
to discuss the benefits of reflective writing and explore some practical examples. The workshop helps students to understand the basics of reflective practice and the research behind reflective practice. Throughout the semester, the students are required to prepare reflection journals every 3 weeks to analyse, reflect and evaluate their learning process. In order to evaluate the students' development of their digital skills through Excel, the instructors have analysed their reflection journals to identify common attributes that they have managed to gain. This analysis may also help the instructors to further improve the activities for the coming semester to further enhance the student digital skills. In part III of this paper, a detailed methodology used to measure qualitatively the development of the students is presented.

Table 1. Mapping of activities in introduction to engineering and industrial seminar and profession courses

\begin{tabular}{|c|c|c|}
\hline $\begin{array}{l}\text { Week } \\
\text { No. }\end{array}$ & ITE & ISP \\
\hline 1 & $\begin{array}{l}\text { Introduction to syllabus, personal information } \\
\text { form, index of learning styles, team for- } \\
\text { mation, cooperative learning }\end{array}$ & $\begin{array}{l}\text { Seminar on semester system, outcome-based edu- } \\
\text { cation }\end{array}$ \\
\hline 2 & Engineering overview assignment & Workshop on information searching from library \\
\hline 3 & $\begin{array}{l}\text { Chemical engineering and } 5 \mathrm{M} \text { concept, Intro- } \\
\text { duction to CBPL }\end{array}$ & $\begin{array}{l}\text { Seminar and workshop on reflection journal and } \\
\text { search engine }\end{array}$ \\
\hline 4 & $\begin{array}{l}\text { CPBL project stage 1-phase } 1 \text { (student meet } \\
\text { problem), basic engineering calculations }\end{array}$ & $\begin{array}{l}\text { Engineering overview and experience sharing by } \\
\text { practising engineer }\end{array}$ \\
\hline 5 & CPBL project stage 1-phase 2 (progress) & Basic engineering calculations using Excel \\
\hline 6 & $\begin{array}{l}\text { CPBL project stage 1-phase } 3 \text { (presenta- } \\
\text { tion), CPBL project stage 2-phase } 1 \text { (under- } \\
\text { stand additional information) }\end{array}$ & $\begin{array}{l}\text { Effective PowerPoint presentation and public } \\
\text { speaking }\end{array}$ \\
\hline 7 & $\begin{array}{l}\text { CPBL project stage 2-phase } 2 \text { (progress - } \\
\text { audit and data collection) }\end{array}$ & $\begin{array}{l}\text { Talk from experts on sustainability issue of the } \\
\text { CPBL project }\end{array}$ \\
\hline 8 & Learning about process and process variables & Industrial visits to sites related to CPBL project \\
\hline 9 & $\begin{array}{l}\text { Revision on basic engineering calculations } \\
\text { and process variables }\end{array}$ & Problem solving using TRIZ \\
\hline 10 & $\begin{array}{l}\text { CPBL project stage 2-phase } 3 \text { (presenta- } \\
\text { tion), CPBL project stage 3-phase } 1 \text { (final so- } \\
\text { lution) }\end{array}$ & Seminar on sustainable development \\
\hline 11 & CPBL project stage 3-phase 2 (progress) & $\begin{array}{l}\text { Forum on success and failure factors in university } \\
\text { with seniors and alumni }\end{array}$ \\
\hline 12 & $\begin{array}{l}\text { CPBL project stage 3-phase } 2 \text { (progress), } \\
\text { assignment on code of ethics }\end{array}$ & Seminar on code of ethics \\
\hline 13 & $\begin{array}{l}\text { CPBL project stage 3-phase } 3 \text { (presenta- } \\
\text { tion), }\end{array}$ & \\
\hline 14 & No class & Exhibition and poster presentation \\
\hline
\end{tabular}




\section{$3 \quad$ Methodology}

Microsoft Excel seminar is not taught like a traditional lecture course, but rather a hands-on instruction. Students therefore benefit from learning by doing, where an instructor provides hands-on assistance and conducts a tutorial to support student's need. This learning instruction assumes that the students do not have any prior experience working with spreadsheets. The instructions in seminar allows students to gain confidence with the software by solving problems that are approachable.

The Excel seminar has been introduced to be approachable for first year chemical engineering students with minimal experience in using spreadsheets. The seminar is taught with the expectation that students will need to learn basic Excel skills and to help students irrespective of their level of digital proficiency.

The seminar guides the students through discovering the basic knowledge of the spreadsheet. The seminar also allows students to explore different functions that are available in the software. Students work through a problem step-by-step along with the instruction given. Then, the students will try to solve a problem on their own.

Take home assignment is given after the 3-hour seminar. The assignment is designed to evaluate students' Excel competency. Students are given two weeks to complete the assignment. Students are required to write and submit their second individual journals at the end of week seven. The purpose of the reflective journal is to develop students' critical reflection on the learning experience and self-assessment on their digital skills.

This study was conducted on first year chemical engineering students in the ITE and ISP courses during the $2019 / 2020$ and 2020/2021 session. To study the impact of the course, the students were asked to write reflective journals on what they have learnt. The two years' data, Semester 2019/2020 and Semester 2020/2021 were collected from reflective journals written by students of different batch. The qualitative analysis of journal data provided a useful way for students to express their views and reflect their behaviors and observation during the learning process. A journal is an important tool to capture students' learning experiences, allow them to contribute to their new learning in a positive manner, clarify learning issues and develop new perspectives [25].

To analyse the journal at the end of the semester, a thematic analysis was adopted in a study. All 135 students from 2019/2020 session and 154 students from 2020/2021 session were submitted their reflection journals. A significant amount of time was spent reading and developing coding by the instructor of the ISP course. The codes were analysed, and were grouped to develop themes. The themes emerged from the process were shared with other researchers to validate the themes generated and increased reliability. The journals were carefully analysed to observe the trend of students' learning experiences. 


\section{$4 \quad$ Results and Discussion}

The written journals were used as the primary data source because they would be able to provide the learning experiences of the respective students regarding the ISP course. The themes emerged from the journals were categorised into a) lacking digital skill proficiency, b) knowledge acquisition, c) assignment, d) facilitation effectiveness, and e) important skills for future career

\subsection{Lacking Digital Skills Proficiency}

Excel competencies is crucial for students because it is one of the most used spreadsheet programs in many classwork. Findings from students' journals revealed that majority of students lacked Excel competency. Despite seemingly being technological savvy, most students entering university lack the necessary computational skills to succeed in engineering programs. Comments about lacking digital skills competency are exemplified in the following quotes from students:

a) Year $2019 / 2020$

- I never use spreadsheet before, and it scares me a lot. I honestly have no idea that I can enter equations and Excel can perform the calculation.

- I have no idea of the Excel functions. It is a great tool to calculate the data accurately and also will save a lot of time.

- I never knew that Microsoft Excel have the function to solve the mathematical problems. I am happy and excited as I have the opportunity to learn it. I think this will be helpful for my career in the future.

- I am very glad that I learn Microsoft Excel in the seminar. I was nervous because I was not familiar with Excel.

- Before attending this seminar, I only knew some basic functions of Microsoft Excel. My skills in utilising Excel had improved after I attended the seminar.

b) Year $2020 / 2021$

- I am actually not that expert using this Microsoft Excel. That is why I was totally excited when I know that there will be a seminar that teach us deeply about Microsoft Excel.

- I did not have any experience on using Excel since my previous study did not require me to use it. That's why I'm so excited to this class.

- Before that, I only use Microsoft Excel to create tables and plot graph. After this seminar, my mind was totally changed. Microsoft Excel is actually a good calculator to let us solve engineering mathematical problem easily. It can solve a lot of complicated problems.

- This was the first time I used Microsoft Excel to calculate the mathematical questions. I knew Microsoft Excel can be used to solve mathematics questions since I was in secondary school but I never tried to use it because I did not know where to start. 
- Before attending the seminar, my understanding towards Microsoft Excel is that it is just merely a tool to draw tables and plot graphs, some operations still require the help of a scientific calculator. It turns out that I was wrong. During the seminar, I was also shocked to find out that we can actually calculate the root of a quadratic equation by using the goal seek function in Microsoft Excel. Hence, I guess my understanding towards Microsoft Excel is not full yet, there are still a lot of useful yet mysterious functions that I can discover in Microsoft Excel.

Interestingly, while many students were found to be very skillful in using the Microsoft Word, some of them did not have any prior knowledge with spreadsheets. According to the survey that have been conducted for 106 students during the 2020/2021 session, when asked about their level of skills and knowledge on spreadsheet softwares, 10 have no skills and experience at all. In addition to that, 62 considered themselves at the beginner level while 33 ranked themselves at the intermediate level. Only 1 student assumed himself/herself as an expert. According to Samuel and Abrams (2015), this lack of skills resulted in increase of anxiety and students spent a massive amount of time to complete an assignment which could distract them from their learning goals [26]. Students in the ITE class were expected to analyse and present their findings from the problem they have to solve. From the journals, it was found that this seminar was helpful in alleviating the student's anxiety in analysing and presenting their findings for the project report.

\subsection{Knowledge Acquisition}

In journals, majority of students acknowledged that the seminar was useful in teaching them the Microsoft Excel. It was discovered that even students who had some advanced knowledge of the spreadsheets, often had no idea of the functionality available to perform data analysis prior to the exposure in the seminar.

a) Year $2019 / 2020$

- I had a slight background in Excel, but now I gain confidence in dealing with data analysis. The knowledge gained in this seminar has helped me succeed in my learning and preparing my PBL report.

- I learnt how to organize data, to perform data analysis of the case study and develop charts and graphs using spreadsheet. I gained a lot of confidence in dealing with data organization and performing data analysis for my project report and presentation.

- By using Microsoft Excel, I learnt how to manage data and lists by creating tables. In addition, Excel allows me to manipulate data using functions available, to create graphs and charts, to manage database and to perform statistical analysis.

- Apparently, Excel is useful to an engineering student especially in calculation since as we do not have to erase and to recalculate everything if we make any mistake.

- Now, I can calculate the mean and mid of a series of numbers very easily and quickly. I also discovered that Microsoft Excel had a lot of mathematical function that can help me in tabulating data and plotting graph. This was not only useful for our PBL project but perhaps in the future projects or assignments. 
Paper-Qualitative Development of Students' Digital Skills by Integrating a Spreadsheet Software in...

- The seminar has helped me on analysing data and I could efficiently tabulate and analyse the data that had been collected for our PBL project.

b) Year 2020/2021

- At the end of the seminar, I was surprised when I found that it was very easy to be learned and very convenient to be used. I found that one of the advantages of using it was when formulating a table of data as the data will be arranged systematically. Some other functions such as finding the roots of the equation by using the Goal Seek function was useful too.

- I've learnt how to construct a table to produce various data from the exist data by using formula. The absolute cell reference knowledge was good to know and extremely useful to create table. Excel can visualise these raw data in the form of pie chart, bar chart, scatter diagram and line graphs. Excel can even find best fit line and roots of equation with certain built-in functions.

- This seminar helps me to explore what I had never exposed to before and drive me to have a strong desire to know more about it. This content indeed helped me a lot in my PBL report as we have to work with massive data and interpret the data in table or chart form.

The findings indicated that students had high motivation in learning to use Microsoft Excel software. The four years of an engineer's degree program are filled with complex math and science. Therefore, students realized that they acquired valuable skills that would assist them in the learning process. To be successful in the chemical engineering program, students are required to be proficient in basic chemical principles and research-based writing skill. Student must possess the digital skills to manage, analyse, and present their findings in a concise manner [26]. Excel is relatively simple tool to demonstrate basic simulation in the classroom and is available at a low cost for university students. Most importantly, Excel can provide a platform for students to solve various engineering problems.

\subsection{Assignment}

Findings showed that the Excel assignment helped and supported students' learning experience and following are some of the students' statements:

a) Year $2019 / 2020$

- The assignments allowed me to use what I had learned and making me to learn more. It had increased my knowledge on the use of the functions in addition to the seminar.

- In this seminar, I felt quite good as being more resourceful but the assignment was not easy. I discover new knowledge when completing the assignment.

- The assignments were quite difficult. Luckily, my friends and instructor were helpful to clarify my confusion. The assignment had really helped me improved my Excel skills. 
- I could save time completing my assignment and report using Microsoft Excel. For example, using Microsoft Excel had really helped me in preparing my PBL report where I could use cell reference in the formula to calculate and to plot graphs.

- The Excel assignments were not easy. For simple problems, I had to do some basic calculations and create charts and graphs. However, for complex problems, I had to follow the correct steps in obtaining precise results by watching the YouTube channel.

b) Year 2020/2021

- I found that the Excel assignment very challenging and useful. It helped me gain a deeper understanding of what I had learned in the workshop by applying that technique and command specifically designed for Excel uses. After finished the Excel assignment, I had more knowledge on working the Microsoft Excel's functions such as using goal seek method to find the root of an unknown. It is totally a new thing for me to learn about.

- When I finished the Excel assignment, I had more knowledge on working the Microsoft Excel's functions. I hope I can participate in this kind of workshop again in the future as to me Microsoft Excel is a soft skill that every engineer should master to become a skillful engineer.

- The instructor gave an assignment based that needed to be done in Excel. Frankly, I was able to explore Excel in a whole new experience because I attained the capability to plot graphs and use Goal Seek Function, which I didn't even know existed before.

Findings revealed that assignment enabled students to acquire knowledge on basic calculation and developed learning skill on Excel. Moreover, it promoted student's communication skills between instructor and other students for clarification and completing their tasks.

\subsection{Facilitation Effectiveness}

Hands-on learning is effective in assisting students to grasp what they were taught. Hands-on learning in seminar had helped students to not only pay attention during the session, but to actually connected and enjoyed what they learnt based on the following statements:

a) Year 2019/2020

- At first, I did not know how powerful the Microsoft Excel could be. But after our instructor explained how to analyse data step-by-step, I learned that Microsoft Excel was actually easy to use.

- The instructor had conducted the seminar slowly and went over the steps to solve problems or equations. Hence, it was easy for me to catch on. The hands-on seminar had helped me to plot the graph easily. Besides, plotting the graph, we can do a lot of calculations in the Excel. How incredible, right? I always question my group mate during the foundation on how to plot a graph with a gradient. I finally found the answer here in the seminar. 
- Our instructor explained to us how to use Microsoft Excel for calculating a lot of data. She gave step-by-step instructions, which I found very helpful. She also showed us how to make a graph using Microsoft Excel. I found having step-by-step instructions really helped in my learning process on how to do the calculations in Microsoft Excel.

b) Year $2020 / 2021$

- During the seminar, I stayed focused to follow the instructor to avoid missing a single thing. I jotted down the steps to key in a formula, followed the demo, and did the exercises given practically on the spot.

- The instructor shared with us how could be Excel helps the calculation become faster and easier. This was the hand-on seminar I felt most awake ever. In the previous seminar, I was somehow at some of the moment felt sleepy whether the speaker is good at catching our attention or not. However, in this seminar, it was a different story!

- I appreciate that we were guided by an experienced instructor on the application of Excel. Even though due to time constraint, he taught us one by one for every important step of using the built-in function to ensure we are completely understanding the way of using it. From his workshop, I knew a quite a lot of different usage of Excel that I never know before and I understand the importance of knowing all this because it related with the engineering calculation that we are going to do later on.

Hands-on learning is a more engaging way to learn. It can lead to increased retention. It is so effective at information retention because it allows students to do trial-and-error and to learn from their mistakes. According to Cridlin (2007), hands-on learning allows learners to incorporate what is being taught into real world situations, thus allowing the student to retain more information [27]. The seminar had allowed the students to become familiar with the software during the hands-on process and acquired the digital skills that hopefully will be useful for their future careers.

Several students also provided some recommendations to improve the seminar session. They requested more seminar sessions and more challenging problems to be implemented. Comments about the classroom situation and seminar duration are exemplified in the following quotes from students:

- During the seminar, all students sat in the same big hall, hence, I was shy and afraid to express my opinion. I really hope that the instructor will facilitate each section in a smaller classroom. This approach could be more helpful and useful to us. One of the reasons is that I have more confidence to express my views in a small class.

- Because of the time limit, we are not able to learn more complex problems, which I think is not good enough for us. If we are exposed to more complicated problems, it will help us better to do our assignments in the future. 


\subsection{Important Skills for Future Careers}

Student feedbacks in the journals indicated that the seminar allowed them to develop Excel skills that they identified as necessary for the success in the course and their future careers as engineers. They recognized the skills they are learning will be useful in other courses and future careers and here are some of the students' responses:

a) Year $2019 / 2020$

- After attending the class, I found that if I want to master the Excel skills and I need more practice to achieve this. I hope that I will be able to keep up with the cuttingedge technology as I definitely going to use it a lot in the future.

- As a future engineer, I must use them correctly, so that I can exploit the advantage of having technology to the maximum. I would recommend this class to anyone!

- As a young generation, I should appreciate and use the technology that had already existed to enhance my knowledge. This knowledge will assist me in my future career.

- I feel grateful to have a chance to attend this seminar. I believe in my future career, I may have to plot graphs, to compare data and to create charts for presentations.

- The knowledge gained from the seminar was useful for my future because I now know how to plot graphs easily, which I believe will be a necessary skill for my future career.

b) Year $2020 / 2021$

- Learning to use Excel is important for an engineering student as a lot of calculation is involved in our studies and these can be solved by using Excel. I believed that mastering Excel would also help me in my future career too.

- I hope that I can participant in this kind of workshop again in the future as to me I think the Microsoft Excel is a soft skill that an engineer should master in order to become a talented engineer. I also thought that Microsoft Excel should be used frequently in our daily life because seldom using this application will make us more easily to forget on how to use it.

- It was a life saver, because it saved me a lot of time to sort out the large amount data into easy-to-read graphs. Therefore, I promised myself that I will continue to learn more about the powerful Microsoft Excel and apply it in my future assignments and career.

Over the past decades, industries have digitized their operations and processes. It is a crucial responsibility of higher education in this 21 st century to ensure that graduates equipped with the necessary skills to thrive in an ever-growing digitized economy. Employers expect graduates to understand basic computer software programs that offices typically use, including word-processing and spreadsheets, plus familiarity with the internet. 
Paper-Qualitative Development of Students' Digital Skills by Integrating a Spreadsheet Software in...

\section{Conclusion}

Microsoft Excel skills are important for the engineering student of today and tomorrow. Excel is widely used today in almost every engineering discipline. This study was primarily focusing on students' perceptions of their digital skill enhancement with the introduction of ISP course as part of the integrated courses. In conclusion, based on the findings, the Microsoft Excel seminar in ISP course enhanced students' knowledge in digital skills. Besides, it was found that learning digital skills as first-year students, will enable them to continue using the skills in their future courses, and able to apply in their careers, later. This study did not conduct any quantitative analysis; thus, student's actual competency cannot be concluded. Students' own perceptions of their knowledge and skills may not reflect the reality, and should not be used as the primary evidence that an instructional approach is effective. Consequently, future research studies shall be conducted to further analyse and compare students' perceptions of their digital skill enhancement versus actual competency in real case tasks.

\section{Acknowledgement}

The authors would like to acknowledge the Ministry of Higher Education Malaysia and Universiti Teknologi Malaysia for the approved fund (JPT.S(BPKI)2000/09/01 Jld.28(6)) under grant number Q.J130000.3009.02M27 that makes this research viable.

\section{$7 \quad$ References}

[1] National Policy of Industry 4.0. (2018). Ministry of International Trade and Industry Malaysia.

[2] Malaysian Qualifications $\quad$ Framework (MQF) Version 2.0. Available https://www.mqa.gov.my/pv4/mqf.cfm.

[3] Confederation of British Industry. (2011). Building for Growth: Business Priorities for Education and Skills - Education and Skills Survey 2011.

[4] Confederation of British Industry. (2012) Learning to Grow: What Employers Need from Education and Skills - Education and Skills Survey 2012.

[5] Confederation of British Industry. (2013). Changing the Pace-CBI/Pearson Education and Skills Survey 2013.

[6] Fletcher, A. J., Sharif, A. W. A., Haw, M. D. (2017). Using the Perceptions of Chemical Engineering Students and Graduates to Develop Employability Skills. Educ. Chem. Eng., 18: pp. 11-25. https://doi.org/10.1016/j.ece.2016.07.001

[7] Maitland, G. (2014). Ten Skills Chemical Engineers Should Be Talking About. https://ichemeblog.org/2014/09/18/ten-skills-chemical-enginee rs-should-be-talking-about-day-114/. Accessed on 15 May 2020.

[8] Dewi, C. A., Pahriah, Purmadi, A. (2021). The Urgency of Digital Literacy for Generation Z Students in Chemistry Learning. Int. J. Emerg. Technol. Learn., 16 (11): 88-103. https://doi.org/10.3991/ijet.v16i11

$\underline{.19871}$ 
Paper-Qualitative Development of Students' Digital Skills by Integrating a Spreadsheet Software in...

[9] Drigas, A. S. and Kontopoulou, M-T. L. (2016). ICTs based Physics Learning. Int. J. Eng. Pedag., 6 (3): 53-59.

[10] Laar, E. v., Deursen, A. J. A. M. v., Dijk, J. A. G. M. v., Haan, J. d. (2018). 21st-century digital skills instrument aimed at working professionals: Conceptual development and empirical validation. Telemat. Inform. 35: 2184-2200. https://doi.org/10.1016/ j.tele.2018.08.006

[11] Xu, S., Yang, H. H., Zhu, S. (2019). An Investigation of 21st-century Digital Skills on Digital Citizenship among College Students. 2019 International Symposium on Educational Technology (ISET), Hradec Kralove, Czech Republic, pp. 236-240, 2019. https://doi.org/10.1109/ iset.2019.00056

[12] Dos Santos, M. T., Vianna Jr., A. S., Le Roux, G. A. C. (2018). Programming Skills in the Industry 4.0: Are Chemical Engineering Students Able to Face New Problems?. Educ. Chem. Eng., 22: 69-76. https://doi.org/10.1016/j.ece.2018.01.002

[13] Cress, N. L., Robinson, M. A., Corner, L., Legge, R. L., Ricardez-Sandoval, R. A. (2012). Problem-Solving and Concept Integration using a Computational Tool in First-Year Undergraduate Chemical Engineering. Educ. Chem. Eng., 7: e133-e138. https://doi.org/10.1016/j.ece.2012.05.001

[14] Wong, K.W.W., Barford, J.P. (2010). Teaching Excel VBA as a Problem Solving Tool for Chemical Engineering Core Courses. Educ. Chem. Eng., 5: e72-e77. https://doi.org/10.1016/j.ece.2010.07.002

[15] Castier, M., Amer, M. M. (2011). XSEOS: An Evolving Tool for Teaching Chemical Engineering Thermodynamics. Educ. Chem. Eng., 6: e62-e70. https://doi.org/10.1016/j.ece.2010.12.002

[16] Coronell, D.G., Hariri, M.H. (2009). The chemical engineer's toolbox: a glass box approach to numerical problem solving. Chem. Eng. Educ., 43 (2): 1-7.

[17] Cutlip, M.B., Shacham, M. (2008). Efficient integration of numerical problem solving throughout the chemical engineering curriculum. In: XVII Congresso Brasileiro de Engenharia Quimica-COBEQ, Brazil, paper 2545.

[18] Uddin, Z., Ahsanuddin, M., Khan, D. A. (2017). Teaching physics using Microsoft Excel. Phys. Educ., 52: 053001. https://doi.org/10.1088/1361-6552/aa7919

[19] Frownfelter-Lohrke, C. (2017). Teaching good Excel design and skills: A three spreadsheet assignment project. J. Account. Educ., 39: 68-83. https://doi.org/10.1016/j.jaccedu.2016.12.001

[20] Lantushenko, V., Lipton, A. F., Erkis, T. (2018). Teaching Basic Spreadsheet Skills with Peer Tutoring. Managerial Finance, 44(7): 885-901. https://doi.org/10.1108/mf-06-2017$\underline{0234}$

[21] Formby, S. K., Medlin, B. D., Ellington, V. (2017). Microsoft Excel®: Is It An Important Job Skill for College Graduates?. Inf. Syst. Educ. J., 15 (3): 55-63.

[22] Mohd-Yusof, K., Helmi, S., Jamaludin, M. Z., Harun, N. F. (2011). Cooperative Problembased Learning (CPBL): A Practical PBL Model for a Typical Course. Int. J. Emerg. Technol. Learn, 6 (3): 12-20. https://doi.org/10.3991/ijet.v6i3.1696.

[23] Mohd Yusof, K., Sadikin, A. N.,Phang, F. A., Aziz, A. A. (2016). Instilling Professional Skills and Sustainable Development through Problem-Based Learning (PBL) among First Year Engineering Students. Int. J. Eng. Educ., 32: 333-347.

[24] Mohd-Yusof, K., Alwi, S. R. W., Sadikin, A. N., Aziz, A. A. (2015). Inculcating sustainability among first-year engineering students using cooperative problem-based learning, In J. P. Davim (Ed), Sustainability in Higher Education, Chandos Publishing, Elsevier Ltd., pp. 67-95. https://doi.org/10.1016/b978-0-08-100367-1.00004-4 
Paper-Qualitative Development of Students' Digital Skills by Integrating a Spreadsheet Software in...

[25] Boud, D. (2001) Using journal writing to enhance reflective practice. In L. M. English, M.A Gillen, (Eds). New Directions in Adult and Continuing Education. No.90. Jossey-Bass Ser. John Wiley and Sons, pp. 9-18. https://doi.org/10.1002/ace.16

[26] Samuel, J. R., Binyomin, A. (2015). Teaching Fundamental Skills in Microsoft Excel to First-Year Students in Quantitative Analysis. Chem. Educ. 92 (11): 1840-1845. https://doi.org/10.1021/acs.jchemed.5b00122

[27] Cridlin, L. D. (2007). The Importance of hands-on learning, International Laser Safety Conference, California, USA, pp. 151-156.

\section{Authors}

Aziatul Niza Sadikin is a senior lecturer at School of Chemical and Energy Engineering, Faculty of Engineering, Universiti Teknologi Malaysia (UTM), Johor, Malaysia. She is also a research member of Centre for Engineering Education (CEE), UTM.

Azizul Azri Mustaffa is a senior lecturer at School of Chemical and Energy Engineering, Faculty of Engineering, Universiti Teknologi Malaysia (UTM), Johor, Malaysia. He is also a research member of Process Systems Engineering Centre (PROSPECT), UTM.

Hasrinah Hasbullah is a senior lecturer at School of Chemical and Energy Engineering, Faculty of Engineering, Universiti Teknologi Malaysia (UTM), Johor, Malaysia. She is also a research member of Advanced Membrane Technology Research Centre (AMTEC), UTM.

Zaki Yamani Zakaria is a senior lecturer at School of Chemical and Energy Engineering, Faculty of Engineering, Universiti Teknologi Malaysia (UTM), Johor, Malaysia. He is also the current Director Centre for Engineering Education (CEE), UTM.

Mohd Kamaruddin Abd Hamid was an Associate Professor at School of Chemical and Energy Engineering, Faculty of Engineering, Universiti Teknologi Malaysia (UTM), Johor, Malaysia. He was also a former research member of Process Systems Engineering Centre (PROSPECT), UTM.

Siti Hajjar Che Man is a senior lecturer at School of Chemical and Energy Engineering, Faculty of Engineering, Universiti Teknologi Malaysia (UTM), Johor, Malaysia.

Mimi Haryani Hassim is an Associate Professor at School of Chemical and Energy Engineering, Faculty of Engineering, Universiti Teknologi Malaysia (UTM), Johor, Malaysia. She is also a research member of Institute of Future Energy (IFE), UTM.

Muhammad Arif Ab Aziz is a senior lecturer at School of Chemical and Energy Engineering, Faculty of Engineering, Universiti Teknologi Malaysia (UTM), Johor, Malaysia.

Khairiyah Mohd.Yusof is a Professor at School of Chemical and Energy Engineering, Faculty of Engineering, Universiti Teknologi Malaysia (UTM), Johor, Malaysia. She is also the former Director and a research member of Centre for Engineering Education (CEE), UTM.

Article submitted 2021-05-28. Resubmitted 2021-07-13. Final acceptance 2021-07-14. Final version published as submitted by the authors. 